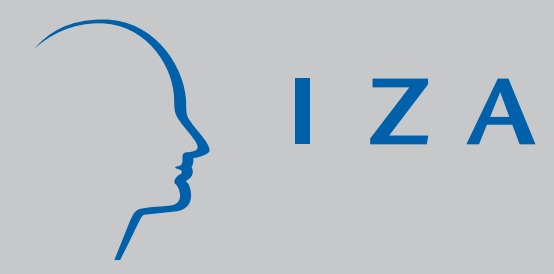

IZA DP No. 2290

Copayments in the German Health System: Does It Work?

Boris Augurzky

Thomas K. Bauer

Sandra Schaffner

September 2006 


\title{
Copayments in the German Health System: Does It Work?
}

\author{
Boris Augurzky \\ RWI Essen \\ and IZA Bonn \\ Thomas K. Bauer \\ RWI Essen, Ruhr-University Bochum, \\ CEPR London and IZA Bonn \\ Sandra Schaffner \\ RWI Essen
}

\section{Discussion Paper No. 2290 \\ September 2006}

\author{
IZA \\ P.O. Box 7240 \\ 53072 Bonn \\ Germany \\ Phone: +49-228-3894-0 \\ Fax: +49-228-3894-180 \\ Email: iza@iza.org
}

\begin{abstract}
Any opinions expressed here are those of the author(s) and not those of the institute. Research disseminated by IZA may include views on policy, but the institute itself takes no institutional policy positions.
\end{abstract}

The Institute for the Study of Labor (IZA) in Bonn is a local and virtual international research center and a place of communication between science, politics and business. IZA is an independent nonprofit company supported by Deutsche Post World Net. The center is associated with the University of Bonn and offers a stimulating research environment through its research networks, research support, and visitors and doctoral programs. IZA engages in (i) original and internationally competitive research in all fields of labor economics, (ii) development of policy concepts, and (iii) dissemination of research results and concepts to the interested public.

IZA Discussion Papers often represent preliminary work and are circulated to encourage discussion. Citation of such a paper should account for its provisional character. A revised version may be available directly from the author. 
IZA Discussion Paper No. 2290

September 2006

\begin{abstract}
Copayments in the German Health System: Does It Work?*

This paper examines the effect of copayments on doctor visits using the German health care reform of 2004 as a natural experiment. In January 2004, copayments of 10 euros for the first doctor visit in each quarter have been introduced for all adults in the statutory health insurance. Individuals covered by private health insurance as well as youths have been exempted from these copayments. We use them as control groups in a difference-indifferences approach to identify the causal impact of these copayments on doctor visits. In contrast to expectations and public opinion our results indicate that there are no statistically significant effects of the copayments on the decision of visiting a doctor.
\end{abstract}

JEL Classification: I11, I18

Keywords: copayment, doctor visits, difference-in-differences, fixed-effect logit

Corresponding author:

Boris Augurzky

RWI Essen

Hohenzollernstr. 1-3

D-45128 Essen

Germany

E-mail: Augurzky@rwi-essen.de

\footnotetext{
* We would like to thank John Haisken-De-New and Harald Tauchmann for their helpful comments and assistance in the data use. Furthermore we are grateful to the Regional Associations of Statutory Health Insurance Physicians for providing data and helpful information.
} 


\section{Introduction}

In many developed countries, health care expenditures have increased more rapidly than GDP in the last decades. The sources of this increase in health care expenditures are manifold. First, technical progress in medicine allows to cure formerly incurable illnesses and to reduce mortality but also increases total costs of the health care system. Second, the demographic change in Germany already led to an ageing population which, on average, results in a higher demand for medical services and products. Since contribution rates to social health insurance in Germany are linked to salaries, health care costs that increase more than salaries lead to higher contribution rates and, thus, to a higher burden for both employees and employers. Furthermore, constantly high unemployment in Germany, which might be partly a result of high contribution rates, reduces revenues of the social health insurance companies adding further pressure on the contribution rates.

Against this background, the German government initiated five major health

care reforms in the 1990s to stop contribution rates from further rising. Despite these efforts average contribution rates increased from $13.2 \%$ in 1995 to $14.3 \%$ in 2003 (Bundesministerium für Gesundheit 2005). Hence, in 2004 another health care reform became effective. An important element of this reform - most controversially discussed in the public - was the introduction of copayments for doctor visits in order to reduce health care costs by creating an incentive to avoid unnecessary doctor visits. Since January 2004, each patient has to pay a flat rate of 10 euros per quarter once she visits a doctor. This paper aims at evaluating the effectiveness of this policy measure.

For the US and Canada, numerous empirical studies exist on the effects of copayments on the number of doctor visits. This literature evaluates the introduction of copayments in these countries in the late 1960's and early 1970's, such as, for example, the Group health plan introduced by the Stanford University in 1967, the Californian Medicaid program introduced in 1972, and the introduction of copayments for doctor visits in the Canadian province Saskatschewan in 1968. Overall, 
the results of these studies indicate that copayments are indeed effective in reducing the number of doctor visits ${ }^{1}$.

Compared to North America, the evidence on the effects of copayments on the usage of the health care system in Germany is rather small. The main reasons for this lack of evidence is that copayments for the utilization of the health care system have been introduced rather late if compared to the US or Canada. Until 2004, only copayments for prescription drugs have been part of the German health care system. Winkelmann (2004) uses the German health care reform of 1997 to examine the impact of copayments for prescription drugs, which have been increased by up to $200 \%$ through this reform, on doctor visits. Using a difference-in-differences strategy to identify the effects of this reform, his results indicate that this policy measure decreased the number of doctor visits by about $15 \%$.

Similar to Winkelmann (2004), this paper uses a difference-in-differences approach to evaluate the effects of the introduction of copayments for doctor visits. The next section describes the health reform of 2004 in more detail. Section 3 presents the data and our identification strategy. The empirical results are discussed in section 4 . Section 5 concludes.

\section{The German health reform 2004}

In Germany, the social health insurance finances roughly $58 \%$ of the total health expenditures of 240 billion euros (Bundesministerium für Gesundheit 2005). Basically, social health insurance is mandatory for all employed workers. Yet, when the salary exceeds a certain threshold, a person can choose whether to remain in the social health insurance system or to opt out and alternatively acquire private health insurance. Independently of their salary, civil servants and self-employed can always choose between social and private health insurance.

The social health insurers calculate income-dependent premiums, so called

\footnotetext{
${ }^{1}$ See, among others, Scitovsky and Snyder (1972), Scitovsky and McCall (1977), Beck (1974), Roemer and Hopkins (1975), and Cherkin, Grothaus, and Wagner (1990).
} 
contribution rates, that do not correspond to individual risks. The payments of the insured are equal to salaries times the contribution rate, up to an income ceiling. Almost half of the premium is paid by employers; the rest is paid by the employee. Roughly 250 health insurers compete with each other on the basis of the contribution rate (Tamm, Tauchmann, Wasem, and Gress 2006). The average contribution rate in 2003 has been 14.3\% (Bundesministerium für Gesundheit 2005). While health expenditures rise more than revenues raised by the premiums due to demographic change, technological progress, unemployment, and system inefficiencies, contribution rates tend to increase. Since the premiums substantially increase labor costs and might be a cause for high unemployment in Germany, the government works against rising contribution rates by regularly undertaking reforms to cut cost. In the 1990s, Germany has experienced five major health reforms.

On the 1st of January 2004 a new health reform became effective, the so-called Gesundheitsmodernisierungsgesetz (law to modernize the health system). Amongst other policy measures it aimed at strengthening the personal responsibility of the insured and introduced a fee of 10 euros for the first doctor visit in a quarter, which covers all therapies within this quarter. ${ }^{2}$ If the therapy continues in the following quarter, the fee has to be paid again. If the patient consults another doctor without having been referred to by the first one, again another fee has to be paid even in the same quarter. Hence, total personal annual expenditures might add up to 40 euros per therapy and year.

Total personal annual expenditures for health services, including e.g. expenditures for pharmaceuticals or hospitals, are, however, capped at $2 \%$ of personal gross income - adjusted for certain deductions. For patients with chronic diseases total expenditures are capped at $1 \%$ of their gross income. Consequently, patients with low income do not have to pay full copayments for doctor visits. Furthermore, there are a few health insurers that exempt their insured from the fee if they participate in certain health programs. Children and teenagers until the age of 18 are exempted

\footnotetext{
${ }^{2}$ The quarter does not start with the beginning of the therapy but is defined by the calendar, with the first quarter starting in January.
} 
from the fee. In addition, persons covered by private health insurance do not pay the fee because they do not belong to the social health system. Thus, youths and privately insured were not affected by the reform and might serve as a valid control group when evaluating the effect of the fee on doctor visits.

Given the changes of the reform of 2004, we expect that the probability to visit a doctor within a quarter decreases for adults covered by social health insurance. Yet, even though the total number of doctor visits should decrease, the number of doctor visits of a person within a quarter should not be affected conditional on having visited a doctor at least once in the quarter. It is unclear whether the effect is larger or smaller for persons with low income. On the one hand, the probability to visit a doctor might decrease more for persons with a low income, because the fee of 10 euros is relatively expensive for them. On the other hand, their reaction might be weaker than average because total health expenditures are capped by $2 \%$ of gross income.

\section{Data and methodology}

To investigate the effects of the copayments introduced in 2004 on the probability of visting a doctor, we employ data from the German Socioeconomic Panel (GSOEP). The GSOEP is an annual representative survey of individuals aged 16 and above which started in 1984. All individuals aged at least 17 years at the time of the interview were asked if and how often they have visited a doctor in the last three months. In most cases, however, the interviews for the GSOEP take place in the first three months of each year. Therefore, the reported number of doctor visits in 2004 partly refers to doctor visits at the end of 2003. Thus, the answers given in 2004 cannot be used to evaluate the effect of the introduction of copayments on doctor visits. We therefore abstained from using data for the year 2004 and used only data for 2003 and 2005.

Table 1 displays descriptive statistics on doctor visits for different subgroups in our sample. The individuals were asked whether they visited any doctor in the last 
three months before the interview and about the number of doctor visits. Between 2003 and 2005 the probability to visit a doctor stayed roughly constant for adults covered by the social health insurance system, while numbers increased slightly for those covered by private health insurance and youths aged 17 . The number of doctor visits in the last three months diminished slightly by approximately $3 \%$ between 2003 and 2005.

Table 2 displays the number of cases of medical treatment collected by four regional Associations of Statutory Health Insurance Physicians. ${ }^{3}$ In all four regions the number of cases of doctoral treatment decreased between 2003 and 2005 by roughly 6 to $7 \%$. Note that we compare only the figures for the 3rd quarter because the number of weekdays and holidays does not change over time in this quarter. The decrease is somewhat larger than that reported in Table 1. Although the differences are small they might be explained by the following. Individuals in the SOEP sample might count their doctor visits only if they were medicated but not if they merely visited an office to get a prescription. The latter, however, are included in the case numbers of the Association of Statutory Health Insurance. Thus, the observed small difference in the number of doctor visits might be explained by the fact that the number of cases without any medication decreased more than those with medication.

This explanation appears to be quite reasonable because the copayments have to be payed for getting a prescription as well. Therefore, patients might attempt to concentrate their visits and to get prescriptions for bigger package sizes. More detailed statistics of the Associations Statutory Health Insurance Physicians show that most pronounced decrease in case numbers is observed for gynecologists. One reason for this decrease is that women have changed from three months birth control pill packages to six months birth control pill packages to avoid copayments every quarter.

\footnotetext{
${ }^{3}$ The 23 regional associations represent the health insurance physicians treating outpatients (family physicians/generals practitioners and specialists). They represent 145,300 doctors and psychotherapists. They manage the billing procedure of health care delivery, distribute the remuneration and conduct contracts at state level with sickness funds and other health care providers.
} 
We use the following variables to control for potential differences between treatment and control group: gender, age, net household income, region, marital status, employment status, highest educational achievement, children, and hours worked per week. We exclude all individuals with missing values on at least one of the variables resulting in a sample size of 18,094 observations for the year 2003 and 16,305 observations for the year 2005. Summary statistics of these variables are provided in the Appendix.

We rely on a difference-in-differences approach to identify the causal effect of the introduction of copayments on doctor visits. The outcome variable is defined as a dummy variable which takes the value 1 if the individual has visited a doctor in the last three months and 0 otherwise. Note that this variable perfectly reflects the incentives introduced by the copayments. After the introduction of the copayments individuals have an incentive to avoid doctor visits in a particular quarter of the year. Once they have visited a doctor in a quarter, additional doctor visits are not subject to the copayment anymore, i.e. conditional on having visited a doctor in a quarter the copayment should have no effect on further doctor visits.

In our empirical analysis, the treatment group includes all individuals covered by statutory health insurance except youths younger than 18. 14,519 observations fall into this group. We use two different kinds of the control groups. The first control group consists of all individuals covered by private health insurance who are at least 18 years old. 1,786 observations fall into this group. Based on this control group we specify the following fixed effects logit model

$$
Y_{i t}=\mathbf{X}_{\mathbf{i t}} \beta+\gamma D_{i t}+\delta_{0} C_{i t}+\delta_{1}\left(D_{i t} \times C_{i t}\right)+\alpha_{i}+\varepsilon_{i t},
$$

where $Y_{i t}$ is the outcome variable for individual $i$ at time $t$ as defined above. $\mathbf{X}_{\mathbf{i t}}$ is a vector of time-variant covariates including household net income, marital status, employment status, number of children aged 6 or younger, hours worked per week, and highest educational achievement. $D_{i t}$ is a dummy variable that takes the value 1 for observations in the year 2005 and 0 otherwise, and $C_{i t}$ is the treatment indicator taking the value 1 for adults covered by statutory health insurance and 0 for adults 
covered by private health insurance. Finally, $\alpha_{i}$ is an individual fixed effect that captures time invariant individual heterogeneity, $\varepsilon_{i t}$ is the stochastic error term. The estimate of $\delta_{1}$ is the difference-in-difference estimator.

The second control group consists of 168 youths aged 17. In this case, we can not employ the panel structure of the data set anymore because the control group is time-variant due to its age restriction. Instead, we pool the data and specify the following logit model

$$
Y_{i}=\mathbf{X}_{\mathbf{i}} \beta+\gamma D_{i}+\delta_{0} C_{i}+\delta_{2}\left(D_{i} \times C_{i}\right)+\varepsilon_{i}
$$

In this model, the DiD estimator is given by $\delta_{2}$. As a specification check of model (2), we restrict the treatment group to only 18 and 19 year old adults because they are more comparable to the control group of youths aged 17 than the whole group of adults.

The key identification assumption of the DiD approach is that the parameters $\delta_{1}$ in model (1) and $\delta_{2}$ in model (2) are zero in the absence of the policy change. This implies that the interaction term must be uncorrelated with the error term. In other words, as the model only includes common time effects captured by the dummy variable $D$, it has to be assumed that conditional on the covariates $X$ there are no unobserved time-varying determinants of the outcome variables with a differential effect on the treatment and control group. This assumption rules out, for example, that changes in the macroeconomic environment display different effects on the two groups or that there are other policy changes that affect the two groups differently. This assumption also rules out that persons covered by social health insurance change the way they count the number of doctor visits because of the reform. If this was the case our estimates would be biased towards zero.

Another substantial part of the German health care reform of 2004 was the increase of copayments on prescription drugs. Similar to the copayments on doctor visits these copayments concern only patients of the social health insurance and might strengthen the effect of the copayments on doctor visits (Winkelmann 2004). 
Other reforms introduced during 2003 and 2005 do not concern doctor visits. Only the labor market reforms have a potential effect on the health care systems because of the contribution rate that is linked to the salaries. However, there is no argument to expect the paid premium to have an effect on doctor visits. Also, changes for recipients of social benefits have no influences on their health care status because their premiums are paid by the employment office if they are not employed and not insured together with a family member. Hence, there appear to be no other changes which influences treatment group and control group in a different way.

A second problem for our identification strategy may occur if the individuals modify their behavior in terms of doctor visits in anticipation of the reform. Our outcome variable is measured one year before the introduction of the copayments. At this point in time, the copayments have not been discussed by German politicians. Even if so, there would hardly have been any incentive to change behavior already at this point in time. Therefore, the problem of anticipation effects (Ashenfelter 1978) should not be of importance for our empirical analysis.

\section{Results}

Table 3 presents summary statistics of the probability to visit a doctor for the three specifications of the control group providing an unconditional difference-indifferences estimate of the treatment effect. The table shows that persons covered by the social insurance system have a significantly higher probability to visit a doctor when compared to persons covered by private health insurance. In addition, adults show a significant higher probability to visit a doctor than youths at the age 17 . No significant differences appear between adults younger than 20 and youths at age 17. Over time, the probability to visit a doctor does not change significantly for neither group. These differences imply positive unconditional DiD-estimates of the treatment effect for all three specifications of the control group. In all cases, however, the unconditional DiD-estimates are not statistically significant.

Table 4 shows an extraction of the results of different conditional DiD estimates 
of the treatment effect. ${ }^{4}$ The second column of the table reports the estimated coefficients of a Logit regression with persons covered by social health insurance as treatment group and persons covered by private health insurance as control group. Different to the unconditional DiD-estimates reported in Table 3, the conditional DiD coefficient is negative and statistically significant, suggesting that the copayments indeed reduced the probability to visit a doctor. However, the estimated DiD coefficient becomes positive and insignificant as soon as we control for individual heterogeneity by estimating a fixed-effect logit model (see column 3 of Table 4). A similar result appears when using the alternative definitions of the treatment and control group. No matter whether we compare adults covered by social health insurance with individuals younger than 18 or adults aged 18 or 19 three months before the interview with youths, the DiD-coefficient appears to be positiv and insignificant (columns 4 and 5 of Table 4 ).

Table 5 displays the results when we allow for heterogenous treatment effects by analyzing different subgroups: men, women, West-Germans, East-Germans, individuals of different education levels, and household income groups, respectively. Throughout Table 5 we are using persons covered by private health insurance as control group. Not controlling for individual heterogeneity we find significant and negative coefficients for the subgroup of West-Germans, individuals with a university degree, and - at a significance level of $10 \%$ - in the lowest income quartile. Note, however, that all estimated treatment effects become insignificant when controlling for individual heterogeneity by estimating a fixed-effect-Logit model.

\section{Conclusion}

Using the German Socioeconomic Panel we investigated the impact of the introduction of a copayment of 10 euros for doctor visits on the probability to visit a doctor. Since youths and persons covered by private health insurance do not have to pay these copayments it is possible to use two different control groups in a

\footnotetext{
${ }^{4}$ The full set of estimation results is available from the authors upon request.
} 
difference-in-differences approach. Our empirical results suggest that the introduction of the copayment did not have a significant effect on the probability of visiting a doctor.Nor for different subgroups of gender, region, education, and income can significant effects be measured if individual heterogeneity is controlled for.

These findings are in contrast to the public opinion and the descriptive statistics stating that the health care reform resulted in a decrease of cases of medical treatment for family doctors as well as medical specialists. This difference might be explained partly by the fact that after the reform patients avoid doctor visits if they only want to collect a prescription by clustering all possible visits to one date and by using bigger package sizes of prescribed drugs. Conditional on any doctor visit within a quarter, however, the number of visits does not alter.

Our findings suggest that the copayments - as introduced in the health care reform of 2004 - appear not to be effective to cut health care costs. We believe that this ineffectiveness is a direct result of the design of the copayments. Patients have to pay the fee only for their first visit of a doctor in a quarter. Empirical results from North America indicate that charging a fee for every doctor visit may be more effective in reducing health care costs even if the copayment per doctor visit is reduced. 


\section{References}

Ashenfelter, O. (1978): "Estimating the Effect of Training Programs on Earnings," Review of Economic Studies, 60, 47-57.

BECK, R. (1974): "The effects of copayment on the poor," Journal of Human Resources, 9, 129-142.

Bundesministerium FÜR Gesundheit (2005): Statistisches Taschenbuch Gesundheit. Bundesministerium für Gesundheit, Berlin.

Cherkin, D. C., L. Grothaus, and E. H. Wagner (1990): "The effects of office visit copayments on preventive care services in HMO," Inquiry, 27(1), 24-38.

Roemer, M., and C. Hopkins (1975): "Copayments for ambulatory care: pennywise and pound-foolish," Medical Care, 13(6), 457-466.

Scitovsky, A. A., And N. MCCALl (1977): "Coinsurance and the demand for physician services: four years later," Social Security Bulletin, 40, 19-27.

Scitovsky, A. A., AND N. SNYDER (1972): "Effect of coinsurance on use of physician services," Social Security Bulletin, 35(6), 3-19.

Tamm, M., H. Tauchmann, J. Wasem, and S. Gress (2006): "Elasticities of Market Shares and Social Health Insurance Choice in Germany: A Dynamic Panel Data Approach," Health Economics, forthcoming.

Winkelmann, R. (2004): "Co-payments for prescription drugs and the demand for doctor visits - Evidence from a natural experiment," Health Economics, 13, $1081-1089$. 
Table 1: Doctor Visits $2003-2005$

\begin{tabular}{|c|c|c|c|}
\hline Year & 2003 & 2004 & 2005 \\
\hline \multicolumn{4}{|c|}{$\begin{array}{l}\text { Social health insurants } \\
\end{array}$} \\
\hline \multirow[t]{2}{*}{ Probability to visit a doctor } & 0.713 & 0.694 & 0.707 \\
\hline & $(0.452)$ & $(0.461)$ & $(0.455)$ \\
\hline \multirow{2}{*}{ Number of doctor visits } & 2.840 & 2.559 & 2.747 \\
\hline & $(4.221)$ & $(3.984)$ & $(4.124)$ \\
\hline Number of observations & 17,351 & 16,855 & 16,061 \\
\hline \multicolumn{4}{|c|}{$\begin{array}{l}\text { Private health insurants } \\
\end{array}$} \\
\hline \multirow[t]{2}{*}{ Probability to visit a doctor } & 0.635 & 0.666 & 0.684 \\
\hline & $(0.481)$ & $(0.472)$ & $(0.465)$ \\
\hline \multirow[t]{2}{*}{ Number of doctor visits } & 2.531 & 2.466 & 2.766 \\
\hline & $(4.082)$ & $(3.958)$ & $(4.453)$ \\
\hline Number of observations & 2,128 & 2,033 & 1,967 \\
\hline \multicolumn{4}{|c|}{$\begin{array}{l}\text { Youths at the age of } 17 \\
\end{array}$} \\
\hline \multirow[t]{2}{*}{ Probability to visit a doctor } & 0.578 & 0.500 & 0.642 \\
\hline & $(0.494)$ & $(0.501)$ & $(0.480)$ \\
\hline \multirow{2}{*}{ Number of doctor visits } & 1.599 & 1.225 & 1.933 \\
\hline & $(2.875)$ & $(1.831)$ & $(3.035)$ \\
\hline Number of observations & 450 & 336 & 558 \\
\hline
\end{tabular}

Notes: Individuals were asked about their doctor visits in the last three months before the interview date. The interview took place at the beginning of each year. Thus, the answers might partly refer to months in the previous year. Source: German Socioeconomic Panel, own calculations. Standard deviations in parentheses. 
Table 2: Summary Statistics of Doctor Visits in Four Regions

\begin{tabular}{llccc}
\hline \hline & & \multicolumn{3}{c}{ 3rd quarter } \\
\cline { 3 - 4 } & & 2003 & 2004 & 2005 \\
\hline Hamburg & Medical specialists & $2,084,253$ & $1,944,188$ & $1,924,407$ \\
& Family doctors & 968,310 & 933,711 & 927,779 \\
& Total & $3,052,563$ & $2,877,899$ & $2,852,186$ \\
Hesse & Medical specialists & $4,749,473$ & $4,390,172$ & $4,408,336$ \\
& Family doctors & $3,949,339$ & $3,746,280$ & $3,722,036$ \\
Schleswig-- & Total & $8,698,812$ & $8,136,452$ & $8,130,372$ \\
Holstein & Medical specialists & $2,314,967$ & $2,145,345$ & $2,188,071$ \\
& Family doctors & $1,818,182$ & $1,728,378$ & $1,702,785$ \\
Westphalia- & Total & $4,133,149$ & $3,873,723$ & $3,890,856$ \\
Lippe & Medical specialists & $6,880,086$ & $6,340,261$ & $6,443,272$ \\
& Family doctors & $5,429,802$ & $5,171,480$ & $5,063,158$ \\
\hline \hline
\end{tabular}

Notes: Data provided by the corresponding regional Association of Statutory Health Insurance Physicians. 
Table 3: Estimation Results

\begin{tabular}{lcc|c}
\hline \hline \multicolumn{3}{c}{ Privately Insured as Control Group } \\
& $(1)$ & $(2)$ & Difference \\
& 2003 & 2005 & $(2)-(1)$ \\
\hline A) Social & 0.705 & 0.708 & 0.003 \\
& $(0.004)$ & $(0.004)$ & $(0.005)$ \\
B) Private & 0.675 & 0.673 & -0.003 \\
& $(0.009)$ & $(0.010)$ & $(0.013)$ \\
\hline Difference (A - B) & 0.030 & 0.036 & 0.006 \\
& $(0.009)$ & $(0.010)$ & $(0.013)$ \\
\hline
\end{tabular}

\begin{tabular}{lcc|c}
\hline \multicolumn{3}{c}{ Youths at the Age of $\mathbf{1 7}$ as Control Group } \\
& $(1)$ & $(2)$ & Difference \\
& 2003 & 2005 & $(2)-(1)$ \\
\hline A) Adults & 0.705 & 0.708 & 0.003 \\
& $(0.004)$ & $(0.004)$ & $(0.005)$ \\
B) Youth & 0.604 & 0.556 & -0.048 \\
& $(0.039)$ & $(0.037)$ & $(0.054)$ \\
\hline Difference (A - B) & 0.101 & 0.152 & 0.050 \\
& $(0.036)$ & $(0.034)$ & $(0.050)$ \\
\hline
\end{tabular}

Youths as Control Group,

18- and 19-Year Old as Treatment Group

\begin{tabular}{lcc|c} 
& $(1)$ & $(2)$ & Difference \\
& 2003 & 2005 & $(2)-(1)$ \\
\hline Adults $<20$ & 0.561 & 0.596 & 0.035 \\
& $(0.032)$ & $(0.041)$ & $(0.052)$ \\
Youth & 0.604 & 0.556 & -0.048 \\
& $(0.039)$ & $(0.037)$ & $(0.054)$ \\
\hline Difference (A - B) & -0.043 & 0.040 & 0.083 \\
& $(0.050)$ & $(0.055)$ & $(0.075)$ \\
\hline \hline
\end{tabular}

Notes: Standard Errors in parentheses. Differences to Table 1 are due to differences in the chosen subsamples. 
Table 4: Selected Results of DiD Regressions with Different Control Groups

\begin{tabular}{|c|c|c|c|c|}
\hline & \multicolumn{2}{|c|}{ Social vs. Private } & \multicolumn{2}{|c|}{ Adults vs. Youths } \\
\hline & Logit & FE-Logit & $\begin{array}{l}\text { All Adults } \\
\text { Logit }\end{array}$ & $\begin{array}{c}<20 \text { yrs } \\
\text { Logit }\end{array}$ \\
\hline DID-coefficient & $\begin{array}{l}-0.233 \\
(2.04)\end{array}$ & $\begin{array}{l}0.065 \\
(0.79)\end{array}$ & $\begin{array}{l}0.405 \\
(1.15)\end{array}$ & $\begin{array}{l}0.724 \\
(1.55)\end{array}$ \\
\hline Year $=2005$ & $\begin{array}{l}0.184 \\
(1.73)\end{array}$ & $\begin{array}{l}-0.024 \\
(0.32)\end{array}$ & $\begin{array}{l}-0.439 \\
(1.26)\end{array}$ & $\begin{array}{l}-0.379 \\
(1.14)\end{array}$ \\
\hline $\begin{array}{l}\text { Social health } \\
\text { insurant }\end{array}$ & $\begin{array}{l}0.260 \\
(2.47)\end{array}$ & $\begin{array}{l}0.219 \\
(1.28)\end{array}$ & - & - \\
\hline 17-years old & - & - & $\begin{array}{l}-0.155 \\
(0.56)\end{array}$ & $\begin{array}{l}0.389 \\
(1.22)\end{array}$ \\
\hline Number of observations & 34,399 & 9,406 & 30,973 & 678 \\
\hline
\end{tabular}

Notes: Absolute z-values are in parentheses. 
Table 5: Summarized Results for Different Subgroups

\begin{tabular}{lcccc}
\hline \hline & \multicolumn{2}{c}{ Logit } & \multicolumn{2}{c}{ FE-Logit } \\
& DiD & Z-value & DiD & Z-value \\
\hline All & -0.233 & -2.04 & 0.065 & 0.79 \\
Men & -0.194 & -1.34 & 0.012 & 0.12 \\
Women & -0.253 & -1.32 & 0.062 & 0.48 \\
West-Germany & -0.247 & -2.00 & 0.056 & 0.64 \\
East-Germany & -0.090 & -0.30 & -0.045 & -0.22 \\
Highest educational achievement & & & & \\
$\quad$ Secondary School & -0.109 & -0.41 & -0.202 & -0.88 \\
Intermediate School & 0.069 & 0.29 & 0.162 & 0.94 \\
Technical School & -0.435 & -0.74 & -0.108 & -0.19 \\
$\quad$ Upper Secondary School & 0.066 & 0.17 & 0.592 & 1.97 \\
$\quad$ University Degree & -0.428 & -2.28 & -0.184 & -1.42 \\
Quantile of household net income & & & & \\
$\quad$ First quartile & -0.665 & -1.92 & -0.629 & -1.39 \\
$\quad$ Second quartile & -0.062 & -0.25 & -0.088 & -0.23 \\
$\quad$ Third quartile & -0.089 & -0.42 & 0.185 & 0.80 \\
$\quad$ Fourth quartile & -0.269 & -1.40 & 0.030 & 0.23 \\
\hline \hline
\end{tabular}




\section{Appendix}

Table 6: Summary Statistics of Selected Variables

\begin{tabular}{lcccccccccc}
\hline \hline & \multicolumn{3}{c}{ Treatment group } & \multicolumn{4}{c}{ Control group } \\
& Social health insurants & \multicolumn{2}{c}{ Private health insurants } \\
& \multicolumn{2}{c}{2003} & \multicolumn{2}{c}{2005} & \multicolumn{2}{c}{2003} & \multicolumn{2}{c}{2005} \\
& Mean & SD & Mean & SD & Mean & SD & Mean & SD \\
\hline Doctor visits last 3 months (yes/no) & 0.705 & 0.456 & 0.709 & 0.454 & 0.657 & 0.475 & 0.671 & 0.470 \\
Gender (male) & 0.457 & 0.498 & 0.456 & 0.498 & 0.611 & 0.488 & 0.614 & 0.487 \\
Age (years) & 48.06 & 17.24 & 48.98 & 17.13 & 48.35 & 14.77 & 48.87 & 14.46 \\
Net Household income (Euro) & 2429 & 1262 & 2361 & 1275 & 3650 & 2076 & 3575 & 1850 \\
West-Germany & 0.722 & 0.448 & 0.717 & 0.451 & 0.863 & 0.344 & 0.866 & 0.341 \\
Married & 0.636 & 0.481 & 0.631 & 0.483 & 0.667 & 0.471 & 0.670 & 0.470 \\
Employed & 0.552 & 0.497 & 0.553 & 0.497 & 0.713 & 0.452 & 0.730 & 0.444 \\
Highest educational achievement & & & & & & & & \\
$\quad$ Secondary School & 0.401 & 0.490 & 0.401 & 0.490 & 0.179 & 0.383 & 0.169 & 0.375 \\
Intermediate School & 0.279 & 0.449 & 0.288 & 0.453 & 0.228 & 0.420 & 0.237 & 0.426 \\
Technical School & 0.026 & 0.158 & 0.028 & 0.165 & 0.036 & 0.186 & 0.036 & 0.186 \\
$\quad$ Upper Secondary School & 0.063 & 0.243 & 0.069 & 0.254 & 0.104 & 0.305 & 0.096 & 0.294 \\
$\quad$ University degree & 0.150 & 0.357 & 0.162 & 0.368 & 0.422 & 0.494 & 0.448 & 0.497 \\
Children (< 6yrs) (yes/no) & 0.169 & 0.469 & 0.155 & 0.447 & 0.173 & 0.482 & 0.163 & 0.458 \\
Hours worked (per week) & 20.36 & 20.78 & 20.00 & 20.82 & 29.73 & 22.74 & 29.53 & 22.62 \\
Number of observations & 16,134 & 14,519 & & 1,960 & & 1,786 \\
\hline \hline
\end{tabular}

